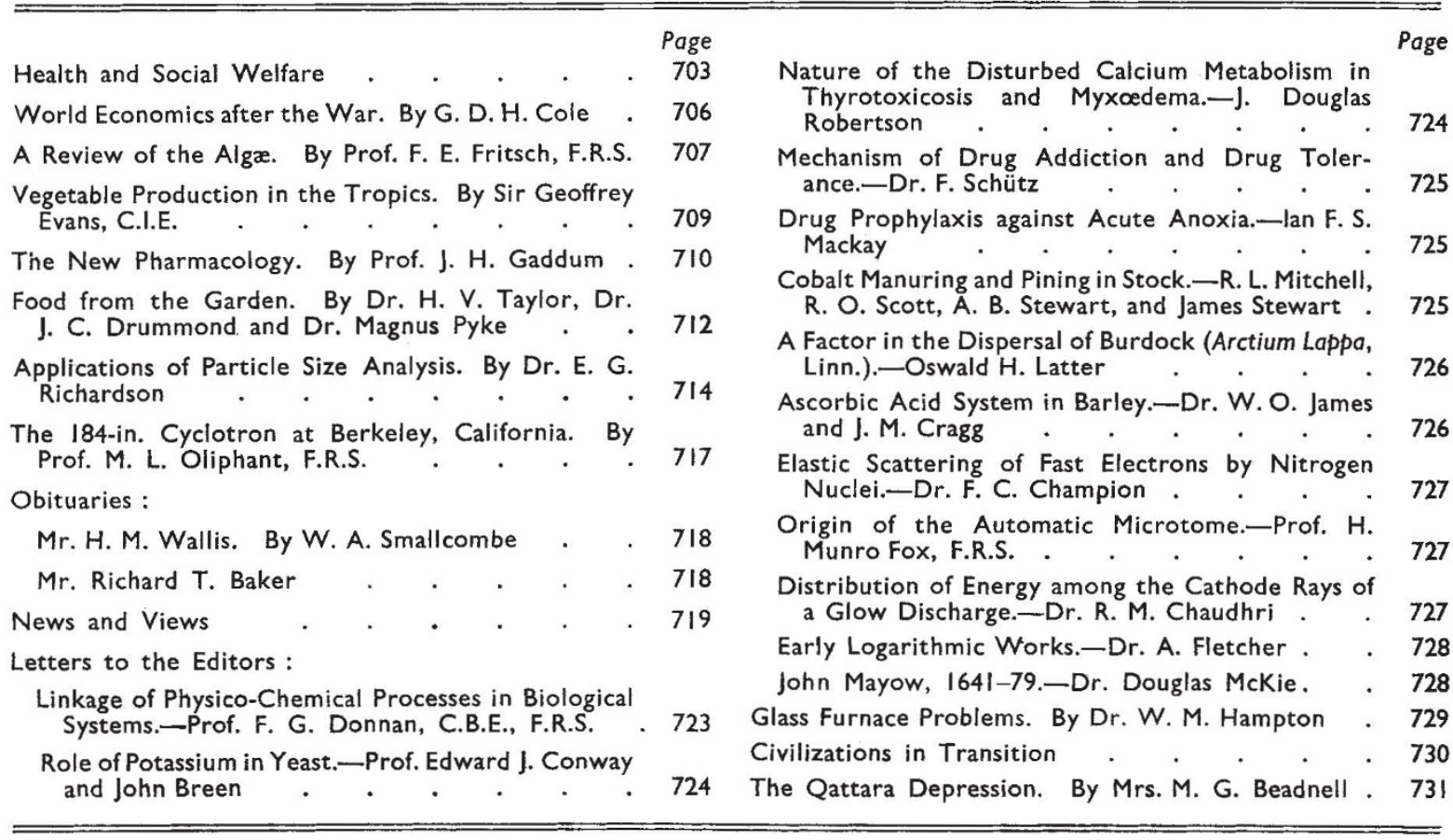

\title{
HEALTH AND SOCIAL WELFARE
}

A LTHOUGH the health of the nation in war has recently been debated in both Houses of Parliament, the attention paid to the subject has scarcely been commensurate with its importance ; indeed it might be held that in this matter Government action is in advance of public opinion. Upon the standard of health depends very largely the volume of production and also the quality of the Fighting Services, yet in the concern over absenteeism, as a report of the Select Committee on National Expenditure indicated, there has been little appreciation of the health factor as the result of excessive hours of work. The precious and vital asset of the good health of the industrial worker is yet to be fully appraised, even if we are more awake to the value of civilian health generally as a result of last winter's experiences.

A further encouraging picture of the nation's health generally has been given by the Chief Medical Officer of the Ministry of Health, while in the recent debate the Minister himself showed that the nation is entitled to congratulate itself on the avoidance of serious epidemics during the second as well as the first year of the War. This second year, moreover, included a period of intense air attack when large sections of the population lived in shelters, often insanitary, and in which material damage coupled with a large re-distribution of the population undoubtedly caused some overcrowding. That the public health has remained so good may well be more a matter of good fortune than of a well-planned policy for the health services, and there can clearly be no relaxation of vigilance. The Minister himself pointed out that good housing is the indispensable foundation of public health, and housing policy is necessarily in suspense.

It should be our first aim, therefore, to utilize this breathing space to adapt our health services to the harder conditions which may lie ahead, and two broadsheets issued by Political and Economic Planning (P E P) are welcome for their contribution to this end. The first of these, on "Health in War-time", points out that the problems of civilian health are potentially far more serious than in the War of 1914-18, mainly because the development of aerial warfare has made the wrecking of civilian community life and services a major objective in the attack on Britain. This is due not merely to the actual damage to public services, such as gas, water, electricity or sewers and consequent deterioration of public hygiene, or to hospitals and clinics, but also to the widespread existence of conditions making for fatigue and loss of satisfactory sleep, and to the indirect effects of the black-out in homes and workplaces in reducing the supply of light and air and assisting the spread of air-borne infections. 
The two major problems, however, are, as in 1914-18, how to ensure adequate nutrition and how to combat fatigue. The nutrition situation is still much better than in 1917-18, and the measures being taken by the Ministry of Food, of which the new scheme for extending the supply of meals and milk for school-children announced by Lord Woolton is a recent example, encourage the hope it may never deteriorate to the same extent. Confidence in this respect is strengthened by the evidence of co-ordinated policy and close collaboration not merely between the Ministry of Food and the Board of Education but also between the Ministry of Food and the Ministry of Transport, as indicated in a subsequent announcement regarding the rationalization of transport to eliminate avoidable cross-hauls and the control of transport of foodstuffs by the Ministry of Food.

The problem of fatigue is probably much more serious. It is estimated that the average adult has lost one hour's sleep a night, and in the bombed areas his sleep is less satisfying than in peacetime. Moreover, hundreds of thousands miss most of their sleep on a number of nights each month because of Home Guard, fire-watching or other civil defence duties. The ratio of civilian food intake to energy output has so far been reduced more from the output and less from the intake end than in 1914-18. Whether this will in the long run reduce physical resistance so as to lead to outbreaks of infection on a large scale is impossible to say. The situation is clearly fraught with longterm dangers and calls for the utmost vigilance, as well as fully justifying all the attention that Lord Woolton is able to give to the variety of diet and the character of nutrition as well as to its amount.

In such circumstances it is of the utmost importance to avoid any unnecessary taxing of health and strength whether in home life or in industry. For this reason alone the recent report of the Chief Inspector of Factories makes somewhat disquieting reading. The Senior Medical Inspector, it is true, finds no evidence that in general the health of the industrial worker has materially suffered in spite of all the adverse circumstances. Night work in itself is not lowering his physical standard, and the effect of long hours on production has led to some relaxation before it has had any real effect on the general health of the worker. Moreover, there is no evidence pointing to any appreciable number of accidents due to nervousness or jumpiness caused by air raids. The evidence is all the other way of courage and spirit in overcoming intense handicaps.

What is disturbing in this report is the evidence of close vigilance that is still required in respect of hours of work, and the alarming wastage of man-power and woman-power through preventible accidents. The question of long hours recurs throughout the report, and while many managements have learnt the lesson that excessive hours diminish production and that proper breaks and rest days are of great importance from the point of view of output alone, there is far too much evidence that other managements have forgotten or appreciate insufficiently the lessons of the War of 1914-18. The observations of the admirable report of the British Association for Labour Legislation issued last year on welfare and health in relation to hours of work and output in wartime remain pertinent. They are supported by a special report on the subject issued by the Industrial Health Research Board, as well as by evidence in the reports of the Select Committee on National Expenditure.

It is clear that in this matter greater stiffness in enforcing good labour conditions would promote production and efficiency as well as morale and health; and a like observation applies to the question of accidents. Fatal accidents rose last year by 24 per cent and non-fatal accidents by 20 per cent over 1939, the figures for which were already 17 per cent and 7 per cent, respectively, higher than in 1938. This increase is attributed to relaxation of care, and particularly the neglect of training in accident prevention among the new industrial workers. While inspectors have to meet some criticism that accident prevention is rather an unworthy subject for consideration in war-time, when men in the Forces are taking every kind of risk, the criticism is unsound; further, as the Chief Inspector points out, the Services are carefully trained not to take unnecessary risks.

What has yet to be realized by management, and sometimes also by workers, is the serious loss of output directly due to accidents caused by lack of reasonable care. This is a matter of increasing importance as the difficulty of replacement of workers and of parts increases. We cannot develop our full man-power and productive capacity until everything that foresight and sound management can suggest has been done to eliminate waste of this character.

This emphasis on the crucial importance of management in regard to health and efficiency is reflected in two other matters bearing on the health of the industrial worker to which reference is made in the same report. The Senior Medical Inspector stresses the need for the extension of a medical service in factories. Much yet remains to be done under the Factories (Medical and Welfare Services) Order of July 1940, and the increasing appointments of medical officers to factories will fail of their full effect without the goodwill and cooperation of both employers and employees. The 
services of fully trained nurses have been greatly extended and they are entering industry in increasing numbers, and if the development of a comprehensive medical service in factories is a long-term policy which cannot be fully achieved in war-time, very considerable advances are none the less possible where managements are alive to the possibilities and realize the opportunities which are theirs through the responsibilities imposed in part under the necessity of civil defence.

The second matter which is one of the responsibilities of management is that of the provision of works canteens. To this subject a special section of the report is devoted. Rationing troubles, twoand three-shift working, travelling hardships, billeting, and bombed homes have made the works canteen an essential in war-time. The difficulties in regard to construction and equipment appear now largely to have been overcome, though resort to mobile canteens may be desirable where a policy of dispersal has aggravated the difficulties. Particularly among the smaller employers, conservatism remains an obstacle, and the factory inspectorate sees no alternative but the extension of communal feeding under the local authorities.

The question of canteens indeed illustrates the way in which the health of the industrial worker is linked up with that of the civil population. The extensions of the selective distribution recently announced by the Ministry of Food should in themselves give a direct impetus to the canteen movement, and the policy of redressing the grievances or inequalities which are inseparable in a uniform rationing system in this way is unquestionably sound. Before the end of the year, eighty-five per cent of miners will be receiving supplementary rations served out at the pithead, and the issue to heavy workers of special rations in their canteens or other catering establishments is sound from the health as well as from the production point of view.

These may be described as a short-time programme, but whether they and the long-term programme for the adequate feeding of children will prove effective depends on other factorscontinued success in the Battle of the Atlantic, the rigorous elimination of waste, effective administration of the policy itself, and not least the progress of our own efforts to increase food production. The marriage of health and agriculture which is being realized under our eyes is one good thing that has come out of the War, like the fuller utilization of our rapidly advancing knowledge of nutrition. The P E P broadsheet rightly lays stress upon the great asset we possess in this respect compared with 1914, particularly through advances in chemotherapy, in blood transfusion techniques, in radiology, in the understanding of problems of industrial health and fatigue and of the mechanisms of the spread of air-borne infections, and other branches of medical science.

This linking up of nutrition and health with agriculture is a noteworthy example of the way in which provision for war-time needs is serving those of long-term policy or reconstruction after the War. The hospital services themselves provide yet another outstanding example; air warfare has already forced upon us a transformation of our medical services. The admirable analysis of the Emergency Hospital Scheme contained in the second P E P broadsheet, on "Hospitals in War Time", not only reviews the scheme in action, but also makes constructive proposals for the improvement of this highly centralized organization.

The first of these proposals is the development of the Emergency Hospital Scheme into a National Hospital Service. The estimates of expected casualties should be reviewed, but the State should continue to pay full treatment costs for Service cases and air-raid casualties, and also for all children, as well as residual costs for full-time civil defence workers, Home Guards, etc. A direct State subsidy to hospitals to maintain their working efficiency is proposed. Changes in central administration involve transforming the E.H.S. Division of the Ministry of Health into a National Hospital and Medical Services Division, and the Ministry would have to play a more positive part to ensure that hospital services everywhere are brought up to an adequate level for the needs of the whole population.

These proposals involve greater regional autonomy and co-ordination. They can only be carried out if the Ministry's regional staffs are strengthened and greater powers delegated to them. The regional and group officers must be carefully selected for administrative ability and be vigorously backed by the Ministry. Other proposals relate to the further development of services : for example, out-patient departments and specialist clinics at appropriate base hospitals, pædiatric services in all reception areas, regional courses on the structure of the E.H.S. and its experiences in action, on war surgery in general, on blood transfusion, poison gas, rehabilitation of the injured and the nursing of war wounds.

Finally, the broadsheet proposes machinery for the planned use of medical man-power, including the transformation of the Central Medical War Committee into a War Medical Service Committee, representing all the interests involved, to determine priorities, to allocate medical men to the various civilian and military services, and to plan their geographical distribution and full employment. Working through regional committees, incorporating the machinery of the existing local 
medical war committees, which register local medical men for national service and recommend how they should be allocated, this proposal might not only facilitate the transference of private practitioners to correspond with the movements of population, but also assist in the use for civilians of medical men in the armed forces who are not fully utilized at present-a question already much discussed by practitioners and social workers and one which may soon become an urgent general question.

Since the broadsheet appeared the Government has announced the broad principles on which its post-war policy will be based. The partnership between the local authorities and the voluntary hospitals is accepted, not merely as the existing basis of the hospital services but as the necessary basis, supplemented by sufficient Government support to ensure that as soon as possible after the War appropriate treatment should be readily available to all in need of it through a comprehensive hospital service. The Government proposes to lay on the major local authorities the duty of securing, in co-operation with the voluntary agencies, the provision of hospital services, and that the service must be designed to serve areas substantially larger than those of individual local authorities, so as to avoid wasteful multiplication of equipment and accommodation. The Government also proposes to secure the provision of the more highly specialized services at teaching hospitals and other selected centres.

These proposals, though less detailed, are clearly in line with the general ideas underlying the recommendations of the $\mathrm{PEP}$ broadsheet. Both sets of proposals visualize the construction of the new hospital service on the experience of the past, and the synthesis of traditions and techniques, previously separate, in the service of a wider movement. Nowhere indeed are there wider possibilities in the building of a healthier social order than in this field of public health, if we but utilize aright the new knowledge and experience of nutrition and healing, of regional organization and administration which lie at our command as a result of research and development, in part through the impact of the War. Social habits, both of diet and of occupation, have been broken down, giving us immense opportunities of raising the whole standard of life and health, if we are ready to seize those opportunities after the War. Nor need we wait until after the War. As Lord Horder has reminded us, in this matter of food and fitness, health and education, child welfare and agriculture, we can begin now in the very service of our war effort.

\section{WORLD ECONOMICS AFTER THE WAR}

Economic Peace Aims : a Basis for Discussion By Oswald Dutch. Pp. 280. (London: Edward Arnold and Co., 1941.) 12s. 6d. net.

$\mathrm{M}^{\mathrm{r}}$ R. DUTCH begins his book with an excellent destructive account of the muddle which was made, especially from the economic point of view, of the settlement of European affairs after the War of 1914-18. This encourages the hope that he will be equally successful in making practical proposals for the settlement after this War. But this hope is disappointed. Mr. Dutch wavers continually between an almost Utopian optimism -as when he proposes that the world shall become practically a free trade area without any barriers in the way of free exchange within about a twelvemonth of the conclusion of hostilities-and a contrasting pessimism which causes him to harp on the dangers of over-production and the need for a universal system of quotas, which are somehow mysteriously to be prevented from operating in the same restrictive fashion as capitalist monopolies have by his own admission been operating in recent years. Again, Mr. Dutch is so haunted by the fear of totalitarianism in all its forms that he appears unable to recognize anything of value in the achievements of the Soviet Union, which he continually brackets with Nazi Germany and Fascist Italy as a horrible example of the destruction of every kind of human liberty.

Mr. Dutch is, in effect, an advocate of controlled capitalism as the instrument of post-war reconstruction over all the world. "The primary and most important fundamental for fixing the status of capital in a new economic plan must be that property remains untouched. There must be no eapital levy, no expropriation, no breaking up of landed property, and no abolition of hereditary rights." In view of this sweeping statement it is not surprising to find that, in spite of his devotion to the cause of liberty, he has no hesitation in recommending the conscription of labour for the work of reconstruction. "It will be advisable not to demobilise these men [the armed forces, except those who have definite jobs to go back to] but to put them to work in groups, under army discipline but at full rates of pay." I fancy that, in all countries, the returning conscripts will have 